\title{
${ }^{137}$ Cs-Based Variation of Soil Erosion in Vertical Zones of a Small Catchment in Southwestern China
}

\author{
Jiacun Chen ${ }^{1,2}$, Zhonglin Shi ${ }^{1, * \mathbb{C}}$, Anbang Wen ${ }^{1}$, Dongchun Yan ${ }^{1}$ and Taili Chen ${ }^{1,2}$ \\ 1 Institute of Mountain Hazards and Environment, Chinese Academy of Sciences, Chengdu 610041, China; \\ chenjiacunzhangrui@163.com (J.C.); wabang@imde.ac.cn (A.W.); yandc@imde.ac.cn (D.Y.); \\ chentaili1994@126.com (T.C.) \\ 2 University of Chinese Academy of Sciences, Beijing 100049, China \\ * Correspondence: shizl@imde.ac.cn; Tel.: +86-137-3080-1305
}

Received: 4 April 2019; Accepted: 13 April 2019; Published: 16 April 2019

check for updates

\begin{abstract}
The study of the variability of soil erosion in mountainous areas provides the basis for soil and water conservation work and forest ecological construction in a targeted way. In this study, Liangshan Town catchment, a typical catchment in the Hengduan Mountains region, southwest China, was selected to investigate the variation of soil erosion in different vertical zones using the ${ }^{137} \mathrm{Cs}$ tracing technique. The mean ${ }^{137} \mathrm{Cs}$ reference inventories varied between 573.51 and $705.54 \mathrm{~Bq} / \mathrm{m}^{2}$, with the elevation increasing from 1600 to $2600 \mathrm{~m}$. The rates of soil erosion exhibited a significant variation. Under the same land cover condition, the average annual soil erosion modulus of high-elevation forest (elevation $>2200 \mathrm{~m}$ ) was $400.3 \mathrm{t} /\left(\mathrm{km}^{2} \cdot \mathrm{a}\right)$. However, the average annual soil erosion modulus of a low-elevation sparse forest (elevation $<1600 \mathrm{~m}$ ) was as high as $1756 \mathrm{t} /\left(\mathrm{km}^{2} \cdot \mathrm{a}\right)$. The average annual soil erosion modulus of the sloping farmland, mainly distributed at elevations of 1600-2200 $\mathrm{m}$, was estimated to be $2771 \mathrm{t} /\left(\mathrm{km}^{2} \cdot \mathrm{a}\right)$. These results indicate that effective soil management measures need to be implemented on the cultivated sloping land in the future.
\end{abstract}

Keywords: variation; soil erosion; fallout radionuclide ${ }^{137}$ Cs; Hengduan Mountains

\section{Introduction}

Soil erosion remains one of the most important environmental problems that threaten the survival and sustainable development of human beings [1,2]. Concerns for the environmental problems associated with soil erosion in agricultural and forest land also directed attention to the impact of soil and water loss in mountainous and sloping farmland, where the soil is more exposed to intense erosion and the sediments from soil erosion have a great effect on the river system [3,4]. Therefore, understanding the key zones of soil and water imbalance is an important requirement [5].

Accelerated soil erosion and degradation caused by excessive land use make soil one of the scarce resources in both developed and developing countries. Therefore, quantitative assessments of soil erosion and the evaluation of the rate of soil loss are urgently needed for effective soil and water conservation measures and sediment management strategies. Despite an apparent progress in the quantification of soil losses and sediment redistribution achieved in China during the past several decades [6,7], an objective knowledge about the intensity of these processes is still insufficient in different landscapes, for example, the Hengduan Mountains area in southwest China [8]. The soils in this region are extremely prone to erosion due to the loose sedimentary rock structure and, especially, the intensive agricultural activities [9]. On-site effects of erosion include soil degradation and the associated crop productivity reduction in this region, while off-site problems include watercourse and reservoir siltation and the eutrophication of water bodies. Previous studies [10,11] have demonstrated 
that the Hengduan Mountains region is one of the main sources of sediment input to rivers such as the Lancang and Yangtze Rivers.

Fallout radionuclides (FRNs), such as ${ }^{137} \mathrm{Cs},{ }^{210} \mathrm{~Pb}_{\mathrm{ex}}$, and ${ }^{7} \mathrm{Be}$, have been widely used for assessing the rates of soil loss at different and temporal scales [12,13]. Anthropogenic fallout radionuclide ${ }^{137} \mathrm{Cs}$ is the most commonly used radionuclide, and its deposition rate on the earth's surface showed a significant peak in $1963[14,15] .{ }^{137} \mathrm{Cs}$ is mainly absorbed by fine soil particles, especially clay minerals, after reaching the ground through dry and wet deposition [16]. It moves slowly in the vertical direction along water seepage and migrates mechanically through physical processes such as the erosion, transport, and deposition of soil particles in space $[17,18] .{ }^{137}$ Cs has proved to be a cost- and time-effective tool to evaluate soil redistribution due to erosion within the landscape and can complement the information provided by conventional erosion measurements and modelling $[19,20]$. This study aimed to quantify the variation of soil erosion and to explore the hotspots of soil loss on a small agricultural catchment of the Hengduan Mountains region, southwest China.

\section{Materials and Methods}

\subsection{Study Area}

The Liangshan Town catchment $\left(4.4 \mathrm{~km}^{2}\right)$, located in the Hengduan Mountains region in Yuanmou County of Yunnan Province (Figure 1), was chosen as the study area. The mean annual temperature and precipitation in the study area were $10.5^{\circ} \mathrm{C}$ and $914.9 \mathrm{~mm}$, respectively. The main soil types are yellow-brown soil and purple soil with bulk densities ranging from 1.2 to $1.4 \mathrm{~g} / \mathrm{cm}^{3}$. The dominant land uses in this catchment area are forestry and cropland, accounting for $80.2 \%$ and $18.4 \%$ of the total area, respectively (Figure 2).

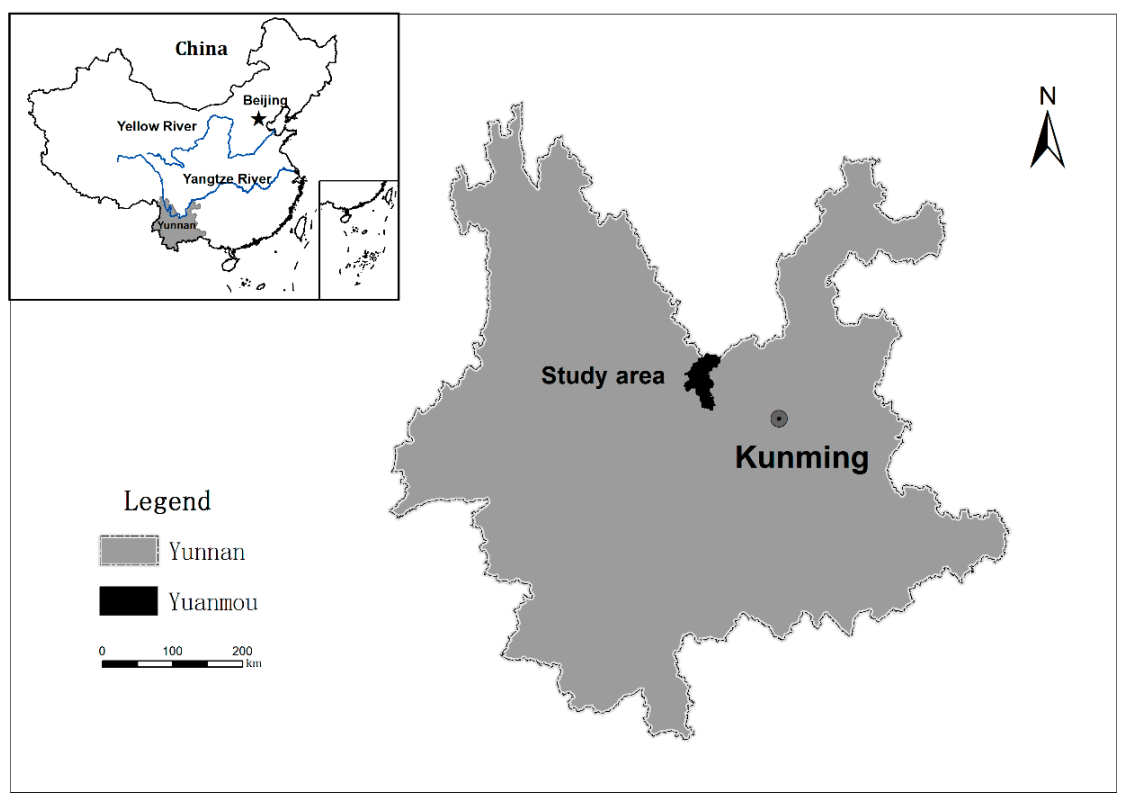

Figure 1. The geographical location of the study area.

The forestland can be divided into two sections according to their elevations, namely the high-elevation forestland (2200-2835 m) and the low-elevation sparse forestland (1350-1600 m). In the former section, the forest is mainly composed of Chir pine, Pinus yunnanensis, and broadleaf tree species (Quercus semecarpifolia and Quercus glauca). However, in the low-elevation sparse forestland section, vegetation is dominated by Dodonaea viscosa shrubs and secondary eucalyptus [21]. 




Figure 2. The land use types in Liangshan Town catchment.

The mid-catchment, with an elevation varying between 1600 and $2200 \mathrm{~m}$, is characterized by cropland in terms of land use. Here, slope-cultivated land occupies $42.3 \%$ of the cropland area, followed by terrace land that occupies $35.6 \%$ and paddy fields that cover $22.1 \%$ of the cropland area.

\subsection{Soil Sampling and ${ }^{137}$ Cs Measurements}

The collection of soil samples from the catchment for ${ }^{137}$ Cs analysis involved two separate sampling strategies. The first was designed to establish the ${ }^{137} \mathrm{Cs}$ reference inventories and their depth distribution in the soil profile. In this case, reference locations with a minimum slope and terrace land were selected for each vertical zone (i.e., $1350-1600 \mathrm{~m}, 1600-2200 \mathrm{~m}$, and 2200-2835 m). The reference sites were sampled using a grid design to collect 5-10 samples, including one depth incremental sample for each vertical section. The sampling depths were $20-30 \mathrm{~cm}$ for forested sites and $30-40 \mathrm{~cm}$ for terrace land. The depth incremental samples were sectioned at 2-cm intervals. The second sampling strategy involved a coring program to establish the magnitude of soil redistribution rates within the catchment. In this case, the catchment was divided into several sampling units based on land use types (i.e., forest or cropland), and a minimum of 10 samples were taken for each unit. All samples were collected using a 7-cm diameter stainless steel coring device.

All samples were air-dried, disaggregated, and passed through a 2-mm sieve prior to a determination of their ${ }^{137} \mathrm{Cs}$ activity by gamma spectrometry using a hyperpure lithium-drifted germanium detector (ORTEC, Oak Ridge, TN, USA). A sample weight of approximately $250 \mathrm{~g}$ and a counting time of over $35,000 \mathrm{~s}$ provided results with an analytical error of approximately $\pm 6 \%$ at the $95 \%$ level of confidence.

\subsection{Conversion Models}

A simplified Mass Balance Model [22] is widely used for the assessment of erosion rates on cultivated land, and it is expressed as follows:

$$
A=A_{0}(1-h / H)^{N-1963}
$$

where $A_{0}$ is the ${ }^{137} \mathrm{Cs}$ reference inventory $\left(\mathrm{Bq} \cdot \mathrm{m}^{-2}\right) ; A$ is the ${ }^{137} \mathrm{Cs}$ inventory at an eroding point $\left(\mathrm{Bq} \cdot \mathrm{m}^{-2}\right) ; h$ is the annual soil loss in depth since the year $1963(\mathrm{~cm}) ; H$ is the plough depth $(\mathrm{cm}) ;$ and $N$ is the sampling year. 
For uncultivated soil, the depth distribution of ${ }^{137} \mathrm{Cs}$ in the soil profile is significantly different from that in cultivated soils. Usually, the depth distribution of ${ }^{137} \mathrm{Cs}$ in an undisturbed stable soil exhibits a well-defined exponential decline with depth, described by a Profile Distribution Model:

$$
A_{x}=A_{0}\left(1-e^{-x / h_{0}}\right)
$$

where $x$ is the mass depth from the soil surface $\left(\mathrm{kg} \cdot \mathrm{m}^{-2}\right) ; A_{x}$ is the ${ }^{137} \mathrm{Cs}$ inventory above depth $x$ $\left(\mathrm{Bq} \cdot \mathrm{m}^{-2}\right)$; and $h_{0}$ is the coefficient describing the profile shape $\left(\mathrm{kg} \cdot \mathrm{m}^{-2}\right)$.

\section{Results}

\subsection{Variation of ${ }^{137}$ Cs Reference Inventory}

The regional variability of ${ }^{137} \mathrm{Cs}$ reference inventories in China were mainly related to rainfall and climate, China's nuclear test in Xinjiang, and the former Soviet Union's nuclear test in Central Asia [23]. Many studies have reported that ${ }^{137} \mathrm{Cs}$ reference inventories in Yunnan province are rather low; the main reasons could be that this region is far away from the nuclear test sites as they are separated by mountains. In addition, because of the influence of the southwest monsoon climate, water vapours mainly come from the low latitude Indian Ocean, where few nuclear tests were conducted.

The moisture-rich monsoon airflow from the Indian Ocean form precipitation when forced to rise upon encountering high mountains. As vertical gradients of elevation in the study area reach more than $1500 \mathrm{~m}$, the precipitation increases with elevation, and the distribution of precipitation varies significantly because of the large fluctuation of terrain. The elevation gradients of the catchment selected in this study range from $1350 \mathrm{~m}$ to $2835 \mathrm{~m}$ along the valley to the summit. The precipitation in the past two years increased from 652.2 to $914.9 \mathrm{~mm}$, increasing by $40.3 \%$ along the valley to the top of the mountain. The ${ }^{137} \mathrm{Cs}$ reference inventories increased by $23 \%$, from 573.5 to $705.5 \mathrm{~Bq} / \mathrm{m}^{2}$ along a $1600-2600-\mathrm{m}$ elevation. The vertical variability of ${ }^{137} \mathrm{Cs}$ reference inventories demonstrated that it was inaccurate to calculate the soil erosion modulus using only one mean value of reference inventories in the whole study area when the elevation and precipitation changed significantly in the vertical, when using the fallout radionuclide ${ }^{137} \mathrm{Cs}$ technique to estimate soil erosion or sediments deposition. In contrast, the design of multilocation and multi-reference inventories was a more reasonable sampling method (Table 1).

Table 1. The background of the ${ }^{137} \mathrm{Cs}$ reference inventory sampling location at different vertical zones.

\begin{tabular}{cccccccc}
\hline $\begin{array}{c}\text { Elevation } \\
(\mathbf{m})\end{array}$ & $\begin{array}{c}\text { Rainfall } \\
(\mathbf{m m})\end{array}$ & Soil Type & Land Use & $\begin{array}{c}\text { Actual } \\
\text { Sample } \\
\text { Size }(\boldsymbol{n})\end{array}$ & CV (\%) & $\begin{array}{c}\text { Minimum } \\
\text { Number of } \\
\text { Samples }\left(\boldsymbol{n}^{\mathbf{}}\right)\end{array}$ & $\begin{array}{c}\mathbf{1 3 7}^{\mathbf{1 3}} \text { Reference } \\
\text { Inventory } \\
\left.\mathbf{( B q} / \mathbf{m}^{\mathbf{2}}\right)\end{array}$ \\
\hline 2600 & 914.9 & Yellow-brown & Forest & 5 & 11.06 & 4.96 & 705.54 \\
2200 & 783.8 & Purple soil & Terrace & 10 & 15.41 & 7.97 & 632.68 \\
1600 & 652.2 & Purple soil & Terrace & 6 & 11.65 & 5.51 & 573.51 \\
\hline
\end{tabular}

American scientist Sutherland [24] pointed out that the sampling method and sample size are primary factors that affect the experimental results of the fallout radionuclide ${ }^{137} \mathrm{Cs}$ technique. However, the sampling method and size of reference inventories are not described in detail in many studies that have applied this method. For reference areas with information on the number of control locations and the estimate of dispersion, the minimum number of samples $\left(n^{\prime}\right)$ necessary to estimate the mean ${ }^{137} \mathrm{Cs}$ baseline inventory with an allowable error of $10 \%$ at a $90 \%$ confidence was determined using the following equation [25]:

$$
n^{\prime}=\left[\frac{t_{(a, n-1)} \cdot C V}{A E}\right]^{2}
$$


where $t$ is the Student's $t$-value for $a=0.10$ (90\% confidence), with $n-1$ degrees of freedom. CV is the coefficient of variation (decimal fraction) and is defined as the standard deviation or arithmetic mean, and $A E$ is the allowable error 0.1 .

Thus, the experimental results are not convincible if it lacks details of the sample method and size of reference inventories, as the estimation of the soil erosion was based on the average value of the reference inventories. Unscientific reference inventories would increase the deviation between the estimated results and the actual values of soil erosion or sediment deposition. Therefore, the dispersion degree of data at the sampling location is a prerequisite to calculate the $C V$ value of the data. The minimum sample size $n$ at a $90 \%$ confidence interval under the $T$ test is calculated based on the $\mathrm{CV}$ value, and the sampling of reference inventories is unrepresentative when the number of samples $(n)$ is less than $n^{\prime}$. The variation coefficients of ${ }^{137} \mathrm{Cs}$ reference inventories at three vertical zones were all within the normal range in this study, with $n>n^{\prime}$.

Figure 3 showed the depth distribution of ${ }^{137} \mathrm{Cs}$ reference inventories at the three sampling locations. The ${ }^{137} \mathrm{Cs}$ reference inventories obtained under the Pinus yunnanensis forest at $2600 \mathrm{~m}$, along a depth distribution, showed a significant variation in the exponential function because this site is covered with the Yunnan pine and is free from human interference due to its high elevation. The ${ }^{137} \mathrm{Cs}$ activities of surface soil were the highest and reached up to $13.2 \mathrm{~Bq} / \mathrm{kg}$. The ${ }^{137} \mathrm{Cs}$ activity values decreased exponentially with an increasing soil depth up to a 14-cm depth. The curve presented a typical depth variation of ${ }^{137} \mathrm{Cs}$ in uncultivated soil, which indicated that the sampling sites had not been disturbed by human activities in the past 50 years. The depth distribution of ${ }^{137} \mathrm{Cs}$ reference inventories obtained at $2200 \mathrm{~m}$ and $1600 \mathrm{~m}$ varied in a pattern typical of cultivated land. The ${ }^{137} \mathrm{Cs}$ activity values in the agricultural layer (approx. $15 \mathrm{~cm}$ ) were uniform and decreased dramatically below the agricultural layer. It was confirmed that the two reference locations were old terraced fields that had not been changed artificially in the past 50 years; these locations were suitable as reference sites for ${ }^{137} \mathrm{Cs}$ at this elevation and were identified after inquiring with local farmers and investigations.

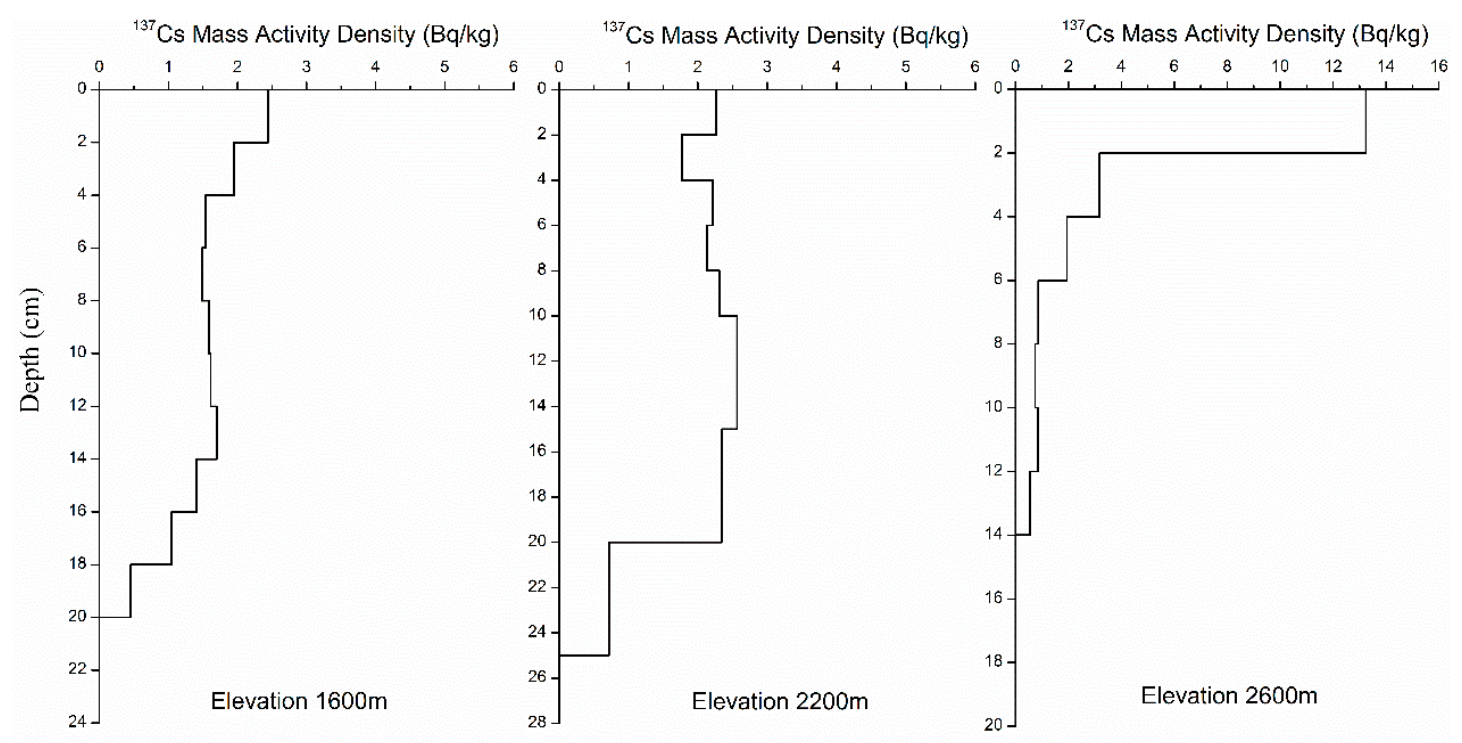

Figure 3. The depth distribution of ${ }^{137} \mathrm{Cs}$ reference inventories (where $1600 \mathrm{~m}, 2200 \mathrm{~m}$, and $2600 \mathrm{~m}$ represent the elevations of ${ }^{137} \mathrm{Cs}$ reference locations).

\subsection{Variability of Soil Erosion Modulus in Different Vertical Zones}

The average annual soil erosion modulus was calculated by comparing the ${ }^{137} \mathrm{C}$ s inventory values under different land use types and the ${ }^{137} \mathrm{Cs}$ reference inventory in the corresponding vertical zones. The greater the difference between the ${ }^{137} \mathrm{Cs}$ area activity density and the ${ }^{137} \mathrm{Cs}$ reference inventory value, the more intense the soil erosion of the slope soil was (Figure 4). The average annual soil 
erosion modulus of a high-elevation forest (elevation $>2200 \mathrm{~m}$ ) was $400.3 \mathrm{t} /\left(\mathrm{km}^{2} \cdot \mathrm{a}\right.$ ), while that of a low-elevation sparse forest (elevation $<1600 \mathrm{~m}$ ) was as high as $1756 \mathrm{t} /\left(\mathrm{km}^{2} \cdot \mathrm{a}\right.$ ) with less annual rainfall. The average annual soil erosion modulus of a sloping farmland was $2771 \mathrm{t} /\left(\mathrm{km}^{2} \cdot \mathrm{a}\right)$, which was mainly distributed between 1600 and $2200 \mathrm{~m}$. Thus, the value of $632.7 \mathrm{~Bq} / \mathrm{m}^{2}$ was used as the reference inventory in the calculation process. The steep slope farmland (slope $>15^{\circ}$ ) had an intense soil erosion, with an average annual soil erosion modulus as high as $7282 \mathrm{t} /\left(\mathrm{km}^{2}\right.$.a) (Figure 5).



Figure 4. The variability of the reference inventory and the area activity density of ${ }^{137} \mathrm{Cs}$ under different land use types.



Figure 5. The soil erosion modulus under different land use types. 
Many researchers have used different methods to study soil erosion in the Hengduan Mountains. For example, Wen [26] obtained an average soil erosion modulus of $1668 \mathrm{t} /\left(\mathrm{km}^{2} \cdot \mathrm{a}\right)$ in the upper reaches of Longchuan River, based on the relationship between the sediment transport modulus and catchment area. In this study area, the Liangshan Town catchment, the average soil erosion intensity of a sloping farmland, was $2771 \mathrm{t} /\left(\mathrm{km}^{2} \cdot \mathrm{a}\right)$ over the recent decades, which belonged to moderate erosion intensity; the average soil erosion intensity of a sparse forestland was $1756 \mathrm{t} /\left(\mathrm{km}^{2} \cdot \mathrm{a}\right)$, which belonged to a mild erosion intensity, indicating that the soil erosion situation in this area was not serious.

The soil erosion modulus of an entire catchment can be calculated using the following formula [27]:

$$
E_{w}=\frac{\left(\sum_{i=1}^{n} S_{i} \cdot E_{i}\right)}{S_{\text {tot }}}
$$

where $E_{w}$ is the erosion modulus for the entire catchment or area $\left(\mathrm{t} \cdot \mathrm{km}^{-2} \cdot \mathrm{a}^{-1}\right) ; n$ is the number of sampling units; $S_{i}$ is the surface area of the sampling units; $S_{\text {tot }}$ is the surface area of the entire catchment or area $\left(\mathrm{km}^{2}\right)$; and $E_{i}$ is the average erosion modulus of the representative fields of the sampling unit $i\left(\mathrm{t} \cdot \mathrm{km}^{-2} \cdot \mathrm{a}^{-1}\right)$. The average soil erosion modulus of the entire catchment was $1216.5 \mathrm{t} /\left(\mathrm{km}^{2} \cdot \mathrm{a}\right)$, calculated using Equation (4), which was lower than the values obtained by other researchers in this region (Table 2).

Table 2. The soil erosion modulus of the Liangshan Town catchment.

\begin{tabular}{ccccc}
\hline Land Use Types & High-Elevation Forestland & Sloping Farmland & Low-Elevation Forestland & Total \\
\hline $\begin{array}{c}\text { Surface area }\left(\mathrm{km}^{2}\right) \\
\begin{array}{c}\text { Average erosion modulus } \\
\left(\mathrm{t} \cdot \mathrm{km}^{-2} \cdot \mathrm{a}^{-1}\right)\end{array}\end{array} \mathbf{c}^{2.28}$ & 400.3 & 0.81 & 1.25 & 4.4 \\
\hline
\end{tabular}

The surface area of the village was $0.06 \mathrm{~km}^{2}$, and the soil erosion of the village was neglected.

\section{Discussion}

\subsection{Factors Influencing the Local ${ }^{137}$ Cs Reference Inventory}

The region's representative reference inventory of fallout radionuclide ${ }^{137} \mathrm{Cs}$ was the basis for using the ${ }^{137} \mathrm{Cs}$ technique to estimate the average soil erosion or the deposition rate in recent decades [28]. The reference inventories of radionuclides were significantly different from each other at different longitudes and elevations in the world [29]. Because of the combined actions of different factors, the reference inventories of radionuclides in the same basin still showed a variability, mainly affected by the average annual precipitation, slope, and land use pattern within small catchments [30].

The variability of ${ }^{137} \mathrm{Cs}$ reference inventories were presented as (1) the differences in ${ }^{137} \mathrm{Cs}$ reference inventories between different latitudes and longitudes and between the southern and northern hemispheres, which showed a close relationship with the geographical locations where nuclear tests were conducted in the last century [31]; (2) a variability at different elevations of the same latitude and longitude, with the change in elevation also being the main factor inducing variation in annual precipitation. In areas where wet precipitation takes the leading role, the average annual precipitation was the key factor influencing the ${ }^{137} \mathrm{Cs}$ reference inventories. Related research $[32,33]$ demonstrated that the correlation coefficient of the variation in annual precipitation and the ${ }^{137} \mathrm{Cs}$ reference inventories is 0.5 ; (3) there were significant differences in the reference inventories under different land use types [34]. Related studies indicated that grassland was the most suitable land cover type that reflected the real background value of the region. Normally, flat grassland was the optimum land cover type for sampling ${ }^{137} \mathrm{Cs}$ reference inventories due to its small slope and runoff and slight disturbance level. In forestland, affected by canopy interception, ${ }^{137} \mathrm{Cs}$ reference inventories near tree trunks were higher than that under the canopy, which results in a variation of ${ }^{137} \mathrm{Cs}$ reference inventories within the forestland [35]. In addition, the main roots of woodland trees were mainly distributed in the surface soil and caused ab inconvenience for sample collection. 
Under these circumstances, the terraced fields that had been abandoned for decades or fields that have not been eroded were often considered as sampling sites for reference inventories.

\subsection{Causes of Soil Erosion Within Vertical Zones and Soil Conservation Measures}

The variability of soil erosion showed an obvious vertical zonality. The soil erosion intensity in low-elevation zones was obviously higher than that in high-elevation zones under the same land cover type. ${ }^{137} \mathrm{Cs}$ is mainly absorbed by fine soil particles, especially clay mineral, after reaching the ground. Although the soils in high-elevation zones are dominated by Yellow-brown soils and those in low-elevation zones are dominated by purple soils, there is no significant difference in the clay content between the two soil types [21]. The main reason was that annual rainfall in high-elevation zones was $40 \%$ more than that in low-elevation zones, which led to sufficient soil moisture and high vegetation coverage in high-elevation zones. In addition, the temperature decrease with an increasing elevation and low annual evapotranspiration, which enabled the surface soil to maintain a certain amount of water under very low precipitations in winter, supported the normal growth of plants at high-elevation zones. A high vegetation cover and a complete forest ecosystem were the key factors reducing soil erosion. Because of the special monsoon climate and less rainfall, a high temperature and drought occurred in winter in the low-elevation zones, accompanied by large soil evapotranspiration. As a result, the surface vegetation coverage rate was low and the vegetation was mainly low drought-tolerant shrubs, with fewer herbs and a large area of bare soil. When the summer rainstorm was concentrated, surface erosion and rill erosion were serious.

A sloping farmland had the greatest soil erosion in the catchment. Soil erosion on sloping farmlands was the main source of sediments in the river. The average soil erosion intensity of a sloping farmland in the Liangshan Town catchment was $2771 \mathrm{t} /\left(\mathrm{km}^{2} \cdot \mathrm{a}\right)$, which was less than the values obtained by other researchers in this region. This was mainly due to the gentle slope of the farmland, which was terraced mainly in the Liangshan Town catchment; the farmland that had been effectively maintained by local farmers; the export of rural labour forces in recent decades; and the effect of returning farmland to forest (pasture).

The results of the present study in Liangshan Town catchment showed that the sloping farmland in the mountainside zone and the sparse woodland in the low-elevation zone were the key zones of the soil and water imbalance in Hengduan Mountains, southwest China. Reducing steep the slope tillage, introducing more cash crops and fruit trees, and adjusting the agricultural structure were the effective approaches to reducing soil erosion in the region. In order to control soil erosion in the low-elevation sparse forest zone, the best measures were introducing drought-resistant forest trees and grasses and gully control, such as by planting drought-resistant pioneer plants mainly composed of Gladiolus and Leucaena leucocephala, which can improve the soil-vegetation system structure and change the microclimate. Finally, other economically beneficial trees could be introduced.

In general, steep-sloping farmland and low-elevation sparse forestland should be taken as key areas of soil and water imbalance and effectively harnessed according to local conditions for soil and water conservation in the Hengduan Mountains of southwest China. Although the two soil types of yellow-brown and purple soils have comparable clay contents as indicated above, other properties (e.g., organic matter content and $\mathrm{pH}$ ) that have the potential to affect the adsorption of ${ }^{137} \mathrm{Cs}$ in soils have not been measured in present work, which should be seen as a limitation of this study. Further works are needed to focus on these issues to strengthen the successful use of the ${ }^{137} \mathrm{Cs}$ method in this area.

\section{Conclusions}

In this study, anthropogenic fallout radionuclide ${ }^{137} \mathrm{Cs}$ was used to investigate the variability of soil erosion in Liangshan Town, a small agricultural catchment in Hengduan Mountains. Three ${ }^{137} \mathrm{Cs}$ reference locations along the vertical zones from the summit to the valley were established according to differences in the elevation and rainfall. The results showed that the reference inventory of ${ }^{137} \mathrm{Cs}$ 
increased from $573.51 \mathrm{~Bq} / \mathrm{m}^{2}$ to $705.54 \mathrm{~Bq} / \mathrm{m}^{2}$ with the elevation rising from $1600 \mathrm{~m}$ to $2600 \mathrm{~m}$, indicating a significant variability. In order to accurately calculate the soil erosion modulus of different land-use types under different vertical zones, the ${ }^{137} \mathrm{Cs}$ inventory values in each vertical zone were compared with the ${ }^{137} \mathrm{Cs}$ reference inventory in the corresponding vertical zone. The results showed that a sloping farmland had the most intense soil erosion, making sloping farmland one of the important sources of sediments in the catchment. The average soil erosion intensity of a sloping farmland in this catchment was $2771 \mathrm{t} /\left(\mathrm{km}^{2} \cdot \mathrm{a}\right)$, which belonged to the category of moderate erosion according to the classification of soil erosion intensity. The average annual soil erosion modulus was as high as $7282 \mathrm{t} /\left(\mathrm{km}^{2} \cdot \mathrm{a}\right)$ when the slope of the cultivated land was greater than 15 degrees, which belong to an intense erosion category. The average annual soil erosion modulus of a low-elevation sparse forest zone (elevation $<1600 \mathrm{~m}$ ) was $1756 \mathrm{t} /\left(\mathrm{km}^{2} \cdot \mathrm{a}\right)$, which is significantly higher than that of the high-elevation forest zone (elevation $>2200 \mathrm{~m}$ ) with a value of $400 \mathrm{t} /\left(\mathrm{km}^{2} \cdot \mathrm{a}\right)$.

Author Contributions: J.C. was the main contributor to the experimental process and manuscript; Z.S. contributed to the original ideas and experimental design; A.W. and D.Y. contributed to the review of the manuscript; T.C. contributed to the soil sampling.

Funding: This research was funded by the National Basic Research Programme of China (2015CB452704).

Acknowledgments: The authors would like to thank the assistance of the Gully Erosion and Collapse Experimental Station in Yuanmou Dry-Hot Valley.

Conflicts of Interest: The authors declare no conflict of interest.

\section{References}

1. Lal, R. Soil erosion and the global carbon budget. Environ. Int. 2003, 29, 437-450. [CrossRef]

2. Pimentel, D. Soil Erosion: A Food and Environmental Threat. Environ. Dev. Sustain. 2006, 8, 119-137. [CrossRef]

3. Walling, D.E.; He, Q.; Appleby, P.G. Conversion Models for Use in Soil-Erosion, Soil-Redistribution and Sedimentation Investigations. In Handbook for the Assessment of Soil Erosion and Sedimentation Using Environmental Radionuclides; Springer: Dordrecht, The Netherlands, 2002; pp. 111-164. [CrossRef]

4. Collins, A.L.; Pulley, S.; Foster, I.D.; Gellis, A.; Porto, P.; Horowitz, A.J. Sediment source fingerprinting as an aid to catchment management: A review of the current state of knowledge and a methodological decision-tree for end-users. J. Environ. Manage. 2017, 194, 86-108. [CrossRef]

5. Du, J.; Shi, C.; Zhou, Y. Sediment yield pattern and its controlling factors in the upper Yangtze River. J. Mt. Sci. 2010, 28, 660-667.

6. Wen, A.B.; Zhang, X.B.; Wang, Y.K.; Wang, J.W.; He, Y.R.; Zhang, Y.Y.; Xu, J.Y.; Bai, L.X. Study on sedimentation source using cesium -137 technique in Yungui Plateau Region of upper Yangtze River. J. Soil Water Conserv. 2000, 14, 25-27. [CrossRef]

7. Chai, Z.X.; Fan, J.R. Forecast of soil erosion change in the upper Yangtze River in the coming 50 years. J. Natural Disasters. 2001, 10, 15-19.

8. Zhang, X.B. Status and causes of sediment change in the upper Yangtze River and sediment reduction measures-comparison of Jialing River with Jinsha River. Soil Water Conserv. China. 1999, 2, 22-24.

9. Wen, A.B.; Zhang, X.B.; Li, H.; Walling, D.E.; Qi, Y.Q. Interpreting of variations of ${ }^{137} \mathrm{Cs}^{210} \mathrm{~Pb}_{\mathrm{ex}}$ and fine particle contents in a deposit profile of the Jiulongdian Reservoir, Chuxiong, Yunnan, China. J. Sediment Res. 2008, 6, 17-23. [CrossRef]

10. Du, J.; Shi, C.; Zhang, S.; Zhang, L. Impact of Human Activities on Recent Changes in Sediment Discharge of the Upper Yangtze River. Progress Geogr. 2010, 29, 15-22. [CrossRef]

11. Shi, Z.; Deng, W.; Zhang, S. Spatio-temporal pattern changes of land space in Hengduan Mountains during 1990-2015. J. Geogr. Sci. 2018, 28, 529-542. [CrossRef]

12. Collins, A.L.; Walling, D.E.; Sichingabula, H.M.; Leeks, G.J.L. Using ${ }^{137}$ Cs measurements to quantify soil erosion and redistribution rates for areas under different land use in the Upper Kaleya River basin, southern Zambia. Geoderma 2001, 104, 299-323. [CrossRef] 
13. Gaspar, L.; Navas, A.; Machín, J.; Walling, D.E. Using ${ }^{210} \mathrm{~Pb}_{\mathrm{ex}}$ measurements to quantify soil redistribution along two complex toposequences in Mediterranean agroecosystems, northern Spain. Soil Tillage Res. 2013, 130, 81-90. [CrossRef]

14. Robbins, J. Geochemical and geophysical applications of radioactive lead. In Biogeochemistry of Lead in the Environment; Nriagu, O., Ed.; Elsevier: Amsterdam, The Netherlands, 1978; pp. 285-393.

15. Iurian, A.R.; Mabit, L.; Cosma, C. Uncertainty related to input parameters of ${ }^{137} \mathrm{Cs}$ soil redistribution model for undisturbed fields. J. Environ. Radioact. 2014, 136, 112-120. [CrossRef] [PubMed]

16. Bygaart, A.J.V.; Protz, R. Bomb-fallout ${ }^{137}$ Cs as a marker of geomorphic stability in dune sands and soils, Pinery Provincial Park, Ontario, Canada. Earth Surf. Process. Landforms 2010, 26, 689-700. [CrossRef]

17. Estrany, J.; Garcia, C.; Walling, D.E. An investigation of soil erosion and redistribution in a Mediterranean lowland agricultural catchment using caesium-137. Int. J. Sediment Res. 2010, 25, 1-16. [CrossRef]

18. Navas, A.; López-Vicente, M.; Gaspar, L.; Machín, J. Assessing soil redistribution in a complex karst catchment using fallout ${ }^{137} \mathrm{Cs}$ and GIS. Geomorphology 2013, 196, 231-241. [CrossRef]

19. IAEA (International Atomic Energy Agency). Guidelines for Using Fallout Radionuclides to Assess Erosion and Effectiveness of Soil Conservation Strategies; International Atomic Energy Agency: Vienna, Austria, 2014; pp. 1-224.

20. Lizaga, I.; Gaspar, L.; Quijano, L.; Dercon, G.; Navas, A. NDVI, ${ }^{137}$ Cs and nutrients for tracking soil and vegetation development on glacial landforms in the Lake Parón Catchment (Cordillera Blanca, Peru). Sci. Total Environ. 2019, 651, 250-260. [CrossRef]

21. Su, Z.; Xiong, D.; Zhang, J.; Zhou, T.; Yang, H.; Dong, Y.; Fang, H.; Shi, L. Variation in the vertical zonality of erodibility and critical shear stress of rill erosion in China's Hengduan Mountains. Earth Surf. Process. Landforms 2019, 44, 88-97. [CrossRef]

22. Zhang, X.B.; Higgitt, D.L.; Walling, D.E. A preliminary assessment of the potential for using cesium-137 to estiamte rates of soil erosion in the Loss Plateau of China. Hydrol. Sci. 1990, 35, 243-252.

23. Qi, Y.Q.; Zhang, X.B.; He, X.; Wen, A.B.; Fu, J. ${ }^{137}$ Cs reference inventories distribution pattern in China. Nuclear Tech. 2006, 29, 42-50.

24. Sutherland, R.A. Caesium-137 soil sampling and inventory variability in reference locations: A literature survey. Hydrol. Process. 1996, 10, 43-53. [CrossRef]

25. Sutherland, R.A. Examination of caesium-137 areal activities in control (uneroded) locations. Soil Technol. 1991, 4, 33-50. [CrossRef]

26. Wen, A.B.; Zhang, X.B.; Wang, Y.K.; Huo, T.R.; Wang, J.W. Study on sedimentation delivery ratio in upper Longchuan River of Yungui Plateau Region. J. Soil Water Conserv. 2003, 17, 139-141.

27. Mabit, L.; Bernard, C.; Laverdiere, M.R. Assessment of erosion in the Boyer River watershed (Canada) using a GIS oriented sampling strategy and ${ }^{137}$ Cs measurements. Catena. 2007, 71, 242-249. [CrossRef]

28. Owens, P.N. Spatial variability of caesium-137 inventories at reference sites: an example from two contrasting sites in England and Zimbabwe. Appl. Radiat. Isot. 1996, 47, 699-707. [CrossRef]

29. Loughran, R.J.; Pennock, D.J.; Walling, D.E. Spatial distribution of caesium-137. In Handbook for the Assessment of Soil Erosion and Sedimentation Using Environmental Radionuclides; Zapata, F., Ed.; Springer: Dordrecht, The Netherlands, 2002; pp. 97-109.

30. Mabit, L.; Meusburger, K.; Fulajtar, E.; Alewell, C. The usefulness of ${ }^{137} \mathrm{Cs}$ as a tracer for soil erosion assessment: a critical reply to Parsons and Foster (2011). Earth-Sci. Rev. 2013, 127, 300-307. [CrossRef]

31. Funk, R.; Li, Y.; Hoffmann, C.; Reiche, M.; Zhang, Z.; Li, J.; Sommer, M. Using ${ }^{137}$ Cs to estimate wind erosion and dust deposition on grassland in Inner Mongolia-selection of a reference site and description of the temporal variability. Plant Soil. 2012, 351, 293-307. [CrossRef]

32. Chawla, F.; Steinmann, P.; Pfeifer, H.R.; Froidevaux, P. Atmospheric deposition and migration of artificial radionuclides in Alpine soils (Val Piora, Switzerland) compared to the distribution of selected major and trace elements. Sci. Total Environ. 2010, 408, 3292-3302. [CrossRef]

33. Porto, P.; Walling, D.E.; Callegari, G. Using repeated ${ }^{137} \mathrm{Cs}$ and ${ }^{210} \mathrm{~Pb}_{\mathrm{ex}}$ measurements to establish sediment budgets for different time windows and explore the effect of connectivity on soil erosion rates in a small experimental catchment in Southern Italy. Land Degrad. Dev. 2018, 29, 1819-1832. [CrossRef] 
34. Mabit, L.; Benmansour, M.; Walling, D.E. Comparative advantages and limitations of the fallout radionuclides ${ }^{137} \mathrm{Cs},{ }^{210} \mathrm{~Pb}_{\mathrm{ex}}$ and ${ }^{7} \mathrm{Be}$ for assessing soil erosion and sedimentation. J. Environ. Radioact. 2008, 99, 1799-1807. [CrossRef]

35. Olley, J.; Burton, J.; Smolders, K.; Pantus, F.; Pietsch, T. The application of fallout radionuclides to determine the dominant erosion process in water supply catchments of subtropical south-east Queensland, Australia. Hydrol. Process. 2013, 27, 885-895. [CrossRef] 